\title{
Barrier Factors to the Completion of Diabetes Education in Korean Diabetic Adult Patients: Korea National Health and Nutrition Examination Surveys 2007-2012
}

\author{
Hee-Tae Kim', Kiheon Lee ${ }^{2, *}$, Se Young Jung ${ }^{2}$, Seung-Min Oh', Su-Min Jeong ${ }^{1}$, Yoon-Jung Choi ${ }^{1}$ \\ 'Department of Family Medicine, Seoul National University Hospital, Seoul, Korea \\ ${ }^{2}$ Department of Family Medicine, Seoul National University College of Medicine and Seoul National University Bundang Hospital, Seongnam, Korea
}

\begin{abstract}
Background: Diabetes is a disease with high social burdens and is expected to increase gradually. A long-term management is essential for the treatment of diabetes, requiring patient self-cares. Diabetes education is important for such self-cares, but it does not sufficiently take place. In addition, little studies have been conducted on the barriers to the completion of diabetes education. This study, thus, aimed to analyze the factors related to the completion of diabetes education and investigate its barriers.

Methods: Of 50,405 respondents to the fourth and fifth Korea National Health and Nutrition Examination Survey, a total of 3,820 were selected for the analysis, excluding those aged 29 or younger and those with missing values. The completion of diabetes education was set as a dependent variable and an analysis was made on the factors that affect the dependent variable. A multivariable logistic regression was employed for the analysis.

Results: Lower educational level was associated with less diabetes education, and the degree of diabetes education was lower in the group with male, the group that didn't have a family history or was not aware of a family history, the group that was not currently aware of diabetes and the group without a spouse. There was no difference in the completion of diabetes education by underlying diseases, family income level, age, residing area, economic activity status, insurance coverage, smoking, and drinking.

Conclusion: Diabetes education is of importance for the treatment and management of diabetes. Currently, however, diabetes education is not sufficiently carried out in Korea. The completion rate of diabetes education was low in male, patients without or not knowing a family history, patients who were not currently aware of their diabetes, patients without a spouse, and patients with low educational level. Therefore, encouraging these patients to take the education will be a more effective approach to increase the completion rate of diabetes education.
\end{abstract}

Keywords: Diabetes Mellitus; Education; Barrier 


\section{INTRODUCTION}

Diabetes mellitus is increasing throughout Korea. For example, in the 1970s, the prevalence of diabetes in Korea was approximately $1.5 \%$; $^{1)}$ however, the prevalence of diabetes has continued to increase and, by 2010, the prevalence of diabetes among those aged 30 or older reached 10.1\% (approximately 3.2 million cases). Furthermore, the number of cases is expected to continue to increase and reach 6 million by 2050. ${ }^{2)}$

Diabetes is the fifth leading cause of death in Korea and causes both cerebrovascular and cardiovascular diseases (also major causes of death). ${ }^{3)}$ In addition, $19.2 \%$ of medical expenditures made by the National Health Insurance are used for the treatment of diabetes. Furthermore, patients with diabetes have expenditures 4.6 times higher than that of the general population. $^{4)}$

In addition to high mortality and costs, diabetes is a chronic disease that requires long-term management. Today, patient self-care (including blood glucose self-monitoring, proper diet, appropriate medication and insulin use, physical activity, and foot care) has become an essential part of treatment for diabetes $^{5)}$ and diabetes education is important for patients in performing such activities.

The effect of diabetes education has been documented in several studies. Previous studies have suggested that diabetes education is associated with enhanced disease-related knowledge and self-care behavior, improvement of glycosylated hemoglobin, weight loss, and cost reduction. ${ }^{6-10)}$ Furthermore, in 1998 the World Health Organization stated that patients are entitled to receive education on diabetes ${ }^{11)}$ and the American Diabetes Association as well as the Korean Diabetes Association have pointed out that education is an important part of treatment. ${ }^{12,13)}$

Although the need for diabetes education is increasing, education is often overlooked in Korea. According to a study based on data from 2007 and 2011, the percentage of patients who had received diabetes education was $15 \%$ to $39.4 \%{ }^{4,14)}$ In contrast, the percentage of patients who had received diabetes education in 1998 and 2005 in the US was $45 \%$ and $53.1 \%$, respectively. ${ }^{15)}$ Currently, less than half of diabetic patients in Korea receive education, a rate lower than that of the US.

Previous studies have suggested that several barriers are associated with diabetes education, including geographical distance, area of residence, cost issues, scheduling conflicts, feeling that education is unnecessary, health issues, and hearing impairments, ${ }^{16-19)}$ as well as being male, having a disability, and level of education. ${ }^{20-22)}$ However, the previous studies were based on surveys of diabetic patients or those who were involved in diabetes education and showed inconsistent results. Moreover, few studies have been conducted to assess the barriers to the completion of diabetes education in Korea.
Education is important for diabetes because self-care is essential for the disease. However, diabetes education in Korean is often overlooked and frequently not offered. Furthermore, research on the cause of the disease is limited. Thus, using a nationally representative sample from the Korean National Health and Nutrition Examination Survey (KNHNES), this study aimed to investigate the factors associated with the completion of diabetes education and to determine who requires this education in Korea.

\section{METHODS}

\section{Materials and Data Collection}

The analysis of this study was based on the data from the fourth and fifth KNHNES conducted from 2007 to 2012. The KNHNES is based on Article 16 of the National Health Promotion Act and has been conducted annually since the fourth KNHNES.

A total of 50,405 participants responded to the 4th and 5th KNHNES. Participants who were 29 years old or younger $(n=17,211)$ and participants who were not diabetic $(n=26,597)$ were excluded from the sample. An additional 2,991 respondents with missing data on any variable were exclude. Therefore, data for 3,606 participants were included in the analyses (Figure 1).

The health interview survey and health examination survey of Korean National Health and Nutrition Examination Survey IV and V (2007-2012) $(n=50,405)$

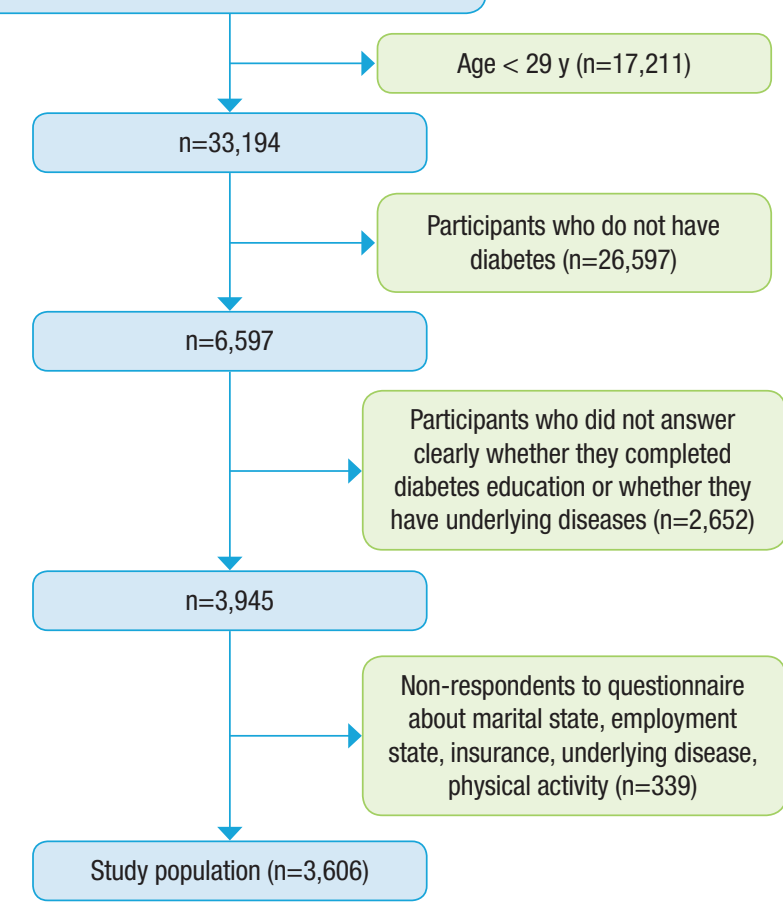

Figure 1. The study population framework. 


\section{Measures and Methods}

1) Health survey

An interview-style questionnaire was used in the KNHNES health survey to measure education, economic activities, and morbidity. Health behavior domains, such as smoking and drinking, were measured by a self-administered questionnaire. This study also examined age, gender, body mass index (BMI), educational level, smoking, drinking, area of residence, underlying disease presence, physical activity, marital status, economic activities, insurance coverage, family history of diabetes, and the awareness of diabetes presence.

Implementation of diabetes education was measured by subjective responses to whether or not participants had completed any diabetes education. The type of education was not measured and patients who completed diabetes self-education were excluded from this study.

(1) Socioeconomic factors and lifestyle risk behaviors

Socioeconomic factors such as age, gender, level of education, family history and household income were examined. Level of education was categorized into 4 groups: university graduation or higher, high school graduation, middle school graduation, and elementary school graduation or lower. The measure of family history used in the KNHNES assessed the status of parents and siblings.

Income level was analyzed based on the quartiles of participant household income. Area of residence was defined as dong or eup/myeon.

Marital status was determined based on the presence of a spouse and employment status was based on current working status. Insurance coverage was assessed by whether participants had medical insurance or medical care assistance. Private insurance was also measured.

Lifestyle risk behaviors, such as drinking, smoking, and lack of physical activity, were also considered. Drinking was divided into two groups: nondrinkers (i.e., those not currently drinking or who have had less than 1 drink per month for the past 1 year) and drinkers (i.e., those who have had more than 1 drink per month for the past 1 year). Smoking was also categorized into 2 groups: current smokers and former/nonsmokers. Physical activity was assessed using the Korean version of the International Physical Activity Questionnaire (IPAQ) short form. The IPAQ was used to calculate the metabolic equivalent of task minutes per week.

\section{(2) Diabetes and underlying disease status}

Patients were defined as having diabetes if they answered that they were diabetic, had a fasting glucose of 126 or over on a blood test, or had glycosylated hemoglobin level of 6.5 or over. Other underlying diseases included hypertension, hyperlipidemia, stroke, myocardial infarction or angina, and chronic re- nal failure. Items were measured by disease prevalence questionnaires. These items were combined into two groups for the analysis: underlying disease (those who had at least one of the underlying diseases) and no underlying disease (those with no underlying disease).

\section{2) Physical measurements and blood testing}

Weight and height were measured according to standardized methods by skilled examiners and used to calculate BMI. Blood tests for glycosylated hemoglobin and fasting glucose (measuring the plasma glucose after 8 hours of fasting) were also used.

\section{Analysis Methods}

The analyses for this study was performed only for patients with complete data. Patients who had missing values on any variable in this study were excluded. After weighting the data, a chi-square test and a t-test were used to assess the relationship between the relevant variables and completion of diabetes education. All variables that reached significance in the univariate analysis were entered in the multivariable logistic regression. No multicollinearity between the variables was found. Statistical significance was set at $\mathrm{P}<0.05$. All analyses were performed using Stata for Windows ver. 12.0 (Stata Co., College Station, TX, USA).

\section{RESULTS}

\section{General Characteristics of Subjects}

The final sample was restricted to 3,606 participants. According to the data from the 2007-2012 KNHNES, the percentage of those who received diabetes education was approximately $15.5 \%$. The univariate analysis showed that the completion of diabetes education was significantly associated with age, family income, educational level, area of residence, family history, marital status, physical activity, and awareness of having diabetes. However, gender, underlying disease status, drinking, smoking, BMI, economic activities, and insurance coverage were not significantly associated with completion of diabetes education (Table 1).

\section{Factors Correlated with the Completion of Diabetes Education}

All variables in the univariate analysis with $\mathrm{P}<0.25$ were included in the multivariable logistic regression analysis. The completion of diabetes education was significantly correlated with gender, marital status, family history, awareness of having diabetes, and educational level. Females reported receiving more diabetes education than males (odds ratio [OR], 1.33; $\mathrm{P}=0.04$ ) and married participants received more diabetes education than those who were not married ( $\mathrm{OR}, 1.39 ; \mathrm{P}=0.02)$. 
Table 1. General characteristics of study subjects $(n=3,606)$

\begin{tabular}{|c|c|c|c|}
\hline \multirow{2}{*}{ Characteristic } & \multicolumn{2}{|c|}{ Diabetes education } & \multirow{2}{*}{ - P-value* } \\
\hline & No & Yes & \\
\hline Age (y) & $59.62 \pm 13.11$ & $57.634 \pm 12.29$ & 0.02 \\
\hline Sex & & & 0.11 \\
\hline Male & 83.68 & 16.32 & \\
\hline Female & 85.88 & 14.12 & \\
\hline Body mass index $\left(\mathrm{kg} / \mathrm{m}^{2}\right)$ & $24.87 \pm 3.78$ & $24.89 \pm 3.38$ & 0.92 \\
\hline Marital status & & & $<0.01$ \\
\hline With spouse & 89.46 & 10.54 & \\
\hline Without spouse $^{\dagger}$ & 83.56 & 16.44 & \\
\hline Education & & & $<0.01$ \\
\hline $\begin{array}{l}\leq \text { Elementary school } \\
\text { graduate }\end{array}$ & 90.12 & 9.88 & \\
\hline $\begin{array}{l}\text { Middle school } \\
\text { graduate }\end{array}$ & 85.16 & 14.84 & \\
\hline High school graduate & 82.25 & 17.75 & \\
\hline$\geq$ College graduate & 75.29 & 24.70 & \\
\hline Household income & & & 0.015 \\
\hline 1st quartile & 87.38 & 12.62 & \\
\hline 2nd quartile & 84.37 & 15.63 & \\
\hline 3rd quartile & 86.21 & 13.79 & \\
\hline 4th quartile & 84.83 & 15.17 & \\
\hline Region & & & 0.069 \\
\hline Urban & 84.07 & 15.93 & \\
\hline Rural & 87.49 & 12.51 & \\
\hline Employment status & & & 0.54 \\
\hline Active & 85.38 & 14.62 & \\
\hline Inactive & 84.42 & 15.58 & \\
\hline Smoking & & & 0.57 \\
\hline $\begin{array}{l}\text { Former smoker and } \\
\text { nonsmoker }\end{array}$ & 84.68 & 15.32 & \\
\hline Present smoke & 85.73 & 14.27 & \\
\hline Drinking & & & 0.92 \\
\hline $\begin{array}{l}\text { Nondrinker and }<1 \\
\text { glass/mo, recent } 1 \text { y }\end{array}$ & 84.97 & 15.03 & \\
\hline$\geq 1$ glass $/ m o$, recent $1 \mathrm{y}$ & 84.82 & 15.18 & \\
\hline Physical activities ${ }^{\ddagger}$ & $2,139.85 \pm 3,625.89$ & $2,404.80 \pm 3,154.91$ & 0.16 \\
\hline Underlying disease $\S^{\S}$ & & & 0.18 \\
\hline Yes & 84.03 & 15.97 & \\
\hline No & 86.15 & 13.85 & \\
\hline Family history & & & $<0.01$ \\
\hline Yes & 79.56 & 20.44 & \\
\hline No or unknown & 86.31 & 13.69 & \\
\hline $\begin{array}{l}\text { Perception of diabetes } \\
\text { mellitus }\end{array}$ & & & $<0.01$ \\
\hline Known & 79.91 & 20.09 & \\
\hline Unknown & 94.46 & 5.54 & \\
\hline Insurance & & & 0.259 \\
\hline National health aid & 85.13 & 14.87 & \\
\hline Medical aid & 81.47 & 18.53 & \\
\hline Private insurance & & & 0.57 \\
\hline Yes & 97.81 & 2.19 & \\
\hline No & 85.37 & 14.63 & \\
\hline
\end{tabular}

Values are presented as mean $\pm S D$ or $\%$.

${ }^{*}$ By t-test for continuous variables; $\chi^{2}$ test for categorical variables. ${ }^{\dagger}$ Divorced+berea

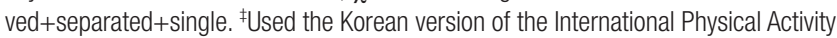
Questionnaire short form to calculate metabolic equivalent of task minutes per week. \&Hypertension, dyslipidemia, stroke, myocardial infarction or angina, chronic kidney disease.
Table 2. Odds ratios (95\% confidence intervals) for diabetes education by multiple factors

\begin{tabular}{|c|c|c|c|}
\hline Variable & Odds ratio & $\begin{array}{c}95 \% \\
\text { Confidence interval }\end{array}$ & P-value* \\
\hline Age & 0.99 & $(0.984-1.010)$ & 0.74 \\
\hline \multicolumn{4}{|l|}{ Sex } \\
\hline Male & 1 & & \\
\hline Female & 1.33 & $(1.014-1.764)$ & 0.04 \\
\hline \multicolumn{4}{|l|}{ Marriage } \\
\hline Without spouse $^{\dagger}$ & 1 & & \\
\hline With spouse & 1.39 & $(1.008-1.939)$ & 0.02 \\
\hline \multicolumn{4}{|l|}{ Region } \\
\hline Urban & 1 & & \\
\hline Rural & 0.89 & $(0.649-1.224)$ & 0.32 \\
\hline \multicolumn{4}{|l|}{ Underlying disease $\mathrm{e}^{\ddagger}$} \\
\hline No & 1 & & \\
\hline Yes & 1.09 & $(0.829-1.434)$ & 0.48 \\
\hline \multicolumn{4}{|l|}{ Family history } \\
\hline No or unknown & 1 & & \\
\hline Yes & 1.39 & $(1.044-1.857)$ & 0.02 \\
\hline \multicolumn{4}{|l|}{ Perception of diabetes mellitus } \\
\hline No & 1 & & \\
\hline Yes & 5.49 & (3.659-8.222) & $<0.01$ \\
\hline \multicolumn{4}{|l|}{ Education } \\
\hline$\leq$ Elementary school graduate & 1 & & \\
\hline Middle school graduate & 1.57 & (1.065-2.325) & 0.023 \\
\hline High school graduate & 2.36 & $(1.638-3.396)$ & $<0.01$ \\
\hline$\geq$ College graduate & 4.19 & $(2.631-6.687)$ & $<0.01$ \\
\hline \multicolumn{4}{|l|}{ Household income } \\
\hline 1st quartile & 1 & & \\
\hline 2nd quartile & 1.003 & $(0.719-1.398)$ & 0.98 \\
\hline 3rd quartile & 0.68 & $(0.464-1.007)$ & 0.055 \\
\hline 4th quartile & 0.91 & (0.629-1.323) & 0.63 \\
\hline
\end{tabular}

Analyzed by multivariable logistic regression.

*By t-test for continuous variables; $\chi^{2}$ test for categorical variables. 'Divorced+berea ved+separated+single. *Hypertension, dyslipidemia, stroke, myocardial infarction or angina, chronic kidney disease.

Subjects with a family history of diabetes received more diabetes education than those without a family history of diabetes/ those who did not know if they had a family history of diabetes (OR, 1.37; $\mathrm{P}=0.02$ ). In addition, those who were aware of their diabetes received more diabetes education than those who were not (OR, 5.49; $\mathrm{P}<0.01$ ) (Table 2).

A statistically significant association was found between education level and diabetes education. The groups with had completed middle school (OR, 1.57; $\mathrm{P}=0.023)$, high school $(\mathrm{OR}, 2.36$; $\mathrm{P}<0.01)$, or university or more $(\mathrm{OR}, 4.19 ; \mathrm{P}<0.01)$ received more diabetes education compared to the group who had completed elementary school or less. However, completion of diabetes education was not significantly associated with physical activity, underlying disease, family income, age, area of residence, employment status, insurance coverage, smoking, or drinking.

\section{DISCUSSION}

An analysis of the nationally representative KNHNES data sug- 
gested that only about $15 \%$ of patients with diabetes in Korea received diabetes education, results that are similar to those found in previous studies conducted with the KNHNES data. ${ }^{14)}$ In addition, this study showed that those with higher education received more diabetes education, findings that are also consistent with those of a previous study ${ }^{20)}$ For example, the present study revealed that those with university graduation or higher received more diabetes education compared to those with elementary graduation or lower. Previous studies have suggested that illiteracy or a low reading comprehension level is a barrier to the completion of diabetes education. For example, one study has shown that low educational level, low reading comprehension level, and high level of educational materials can be a barrier to the completion of diabetes education. ${ }^{23)}$ Another study has indicated that the barriers to the completion of diabetes education included a lack of information on diabetes education and not knowing about the need for the education. ${ }^{16)}$

The results also showed that the group with the lowest educational level received less diabetes education. This may be because physicians may hesitate to prescribe a diabetes education program over concerns about the ability of those with a lower educational level to fully understand diabetes education. The lower educational level group may also have received less diabetes education because the group was not provided with information regarding the importance of a long-term management in diabetes and did not fully recognize the importance of diabetes education.

This study also found that females received more education than males. Previous studies have also suggested that being male is a barrier to the completion of diabetes education..$^{20,21)}$ These previous studies have revealed that physicians are more likely to recommend diabetes education to females than to males; however, according to KNHNES data, men used more medical resources (e.g., medical check-ups) than women. However, given the limited amount of information included in the KNHNES, we were not able to further examine why females completed diabetes education more than males. Further studies are needed in Korea to investigate the differences in the diabetes education completion rates between male and female diabetes patients.

Those with a family history of diabetes also received more diabetes education. Close family members with diabetes may share information regarding the management and treatment of diabetes, including recommendations for diabetes education. In addition, even if one family member is exposed to diabetes, the family may become more interested in the disease and seek more education. This may explain why family history is related to receiving diabetes education.

Marital status was also related to diabetes education, and patients with a spouse received more diabetes education than those without a spouse. However, contrary to the findings of this study, a study conducted in the US suggested that nonmarried people receive more education for diabetes than married people. ${ }^{22)}$ However, this may be related to national and cultural differences. For example, a past study with Mexican American families found that family support is essential to the management of patient self-care. ${ }^{24)}$ This may help explain the why married patients received more diabetes education in this study. If a close family member, such as a spouse, is interested in the health of the patient, the completion rate of diabetes education may increase.

In this study, the percentage of those who were not aware of having diabetes was $71.9 \%$. However, a previous study reported that the rate of awareness of diabetes was $73.4 \%$. $^{2)}$ This difference may be attributable to the exclusion of diabetes patients with missing values. An analysis between the completion of diabetes education and the awareness of having diabetes indicated that those who were aware of their diabetic condition received more education for diabetes. This suggests that those who are not aware that they have diabetes need to be informed of their status, treated, and educated. Nationwide examinations, thorough explanations of the examination results, and followups may help.

This study has some limitations. First, the cross-sectional nature of this study does not allow investigations regarding causality. In addition, there may be a potential for recall bias as the surveys depended on the memory of the subjects. Second, the study did not consider how diabetes education was conducted (i.e., a one-time class versus multiple classes or in a group setting versus an individual setting). However, the differences between such methods have been investigated in previous studies $^{6,25,26)}$ and guidelines regarding a standardized education method have been presented. ${ }^{27)}$ While the KNHNES measured place of education and indicated that most patients received diabetes education in hospitals or clinics, detailed information, such as whether the education was in a group or individual setting and the length of education, was not measured. Third, given that this study used a secondary data source, we were not able to measure several of the barriers to the completion of diabetes education that have been suggested in prior research. For example, previous studies have suggested that geographical distance, area of residence, cost issues, scheduling conflicts, feeling that the education unnecessary, health issues, and hearing impairments ${ }^{16-19)}$ as well as age, gender, disability, and educational level, ${ }^{20-22)}$ are barriers to diabetes education completion. Finally, the present study also found that diabetes education was conducted less frequently among males as well as among those with a lower educational level. However, several other factors were not fully assessed. For example, although family income level was analyzed as a measure of economic status, it did not reflect current asset status nor financial strength, which may explain why no correlation was found in 
the analysis. On the other hand, geographical distance and health issues, as measured by area of residence and underlying disease, respectively, were not correlated with completion of diabetes education. Further studies are needed to assess the relationship between the completion of diabetes education and the type of education method as well as the factors related to the completion of the education.

While previous studies were conducted with only diabetic patients, or in a way that performed a survey on patients or related employees, and carried out in a single hospital or local units, a strength of this study is that the analysis included all diabetic patients who met the operational definition (e.g., blood tests under the circumstance of $70 \%$ of awareness of diabetes) in the nationally representative KNHNES data set. Furthermore, this study analyzed additional variables, such as marital status and family history, which lends additional strength to the analysis.

Previous studies have shown that patients who have completed diabetes education reported improved self-monitoring of blood glucose, proper diet, physical activities, medication compliance, periodic complication diagnosis, waist circumference, and weight maintenance. ${ }^{8,28}$ Furthermore, another study showed that $81 \%$ of patients responded they were satisfied with their diabetes education. ${ }^{29)}$ However, although diabetes education should be offered and recommended to all diabetes patients, its completion rate is still relatively low in Korea. For example, the percentage of those who received diabetes education at least once was $15 \%$ to $40 \%$ in Korea. ${ }^{4,14)}$ In addition, the percentage of patients completing diabetes education decreased between the 4 th and 5th KNHNES (20.24\% to $13.64 \%$, respectively). Furthermore, few studies have been conducted to analyze the cause of this low completion rate.

In order to increase the completion rate, an appropriate intervention is needed for patients who are not aware that they have diabetes. For example, increasing the availability of examinations and treatments across the nation may help to increase the completion rate. In addition, patients with a lower level of education may need more explanation and further recommendations regarding the importance of completing diabetes education. Furthermore, diabetes education should be actively recommended to those without a family history of diabetes and those without a spouse as well as male patients.

\section{CONFLICT OF INTEREST}

No potential conflict of interest relevant to this article was reported.

\section{REFERENCES}

1. Kim K, Choi C, Lee D, Kim E. Epidemiological study on diabetes melli- tus among rural Korean. Korean Diabetes J Assoc 1972;1:17-24.

2. Korean Diabetes Association. Fact sheet: diabetes fact sheet in Korea 2012 [Internet]. Seoul: Korean Diabetes Association; 2012 [cited 2015 Jan 11]. Available from: http://www.diabetes.or.kr/temp/Diabetes_ Fact_sheet2012.pdf.

3. Korea Statistics. Fact sheet: 2013 statics about cause of death [Internet]. Daejeon: Korea Statistics; 2014 [cited 2015 Jan 11]. Available from: http://meta.narastat.kr/metasvc/index.do?confmNo=10154\&inputYe $\operatorname{ar}=2013$.

4. Park IB, Baik SH. Epidemiologic characteristics of diabetes mellitus in Korea: current status of diabetic patients using Korean Health Insurance Database. Korean Diabetes J 2009;33:357-62.

5. World Health Organization. Adherence to long-term therapies: evidence for action [Internet]. Geneva: World Health Organization; 2003 [cited 2014 Jan 21]. Available from: http://whqlibdoc.who.int/publications/2003/9241545992.pdf.

6. Norris SL, Lau J, Smith SJ, Schmid CH, Engelgau MM. Self-management education for adults with type 2 diabetes: a meta-analysis of the effect on glycemic control. Diabetes Care 2002;25:1159-71.

7. Steinsbekk A, Rygg LO, Lisulo M, Rise MB, Fretheim A. Group based diabetes self-management education compared to routine treatment for people with type 2 diabetes mellitus: a systematic review with meta-analysis. BMC Health Serv Res 2012;12:213.

8. Song MS, Song KH, Ko SH, Ahn YB, Kim JS, Shin JH, et al. The longterm effect of a structured diabetes education program for uncontrolled type 2 diabetes mellitus patients: a 4-year follow-up. J Korean Diabetes Assoc 2005;29:140-50.

9. Gary TL, Genkinger JM, Guallar E, Peyrot M, Brancati FL. Meta-analysis of randomized educational and behavioral interventions in type 2 diabetes. Diabetes Educ 2003;29:488-501.

10. Steed L, Cooke D, Newman S. A systematic review of psychosocial outcomes following education, self-management and psychological interventions in diabetes mellitus. Patient Educ Couns 2003;51:5-15.

11. World Health Organization. 1998 Press releases: diabetes and human right [Internet]. Geneva: World Health Organization; 1998 [cited 2014 Apr 22]. Available from: http://www.who.int/inf-pr-1998/en/.

12. American Diabetes Association. Standards of medical care in diabetes--2014. Diabetes Care 2014;37 Suppl 1:S14-80.

13. Korean Diabetes Association. Fact sheet: standards of medical care in diabetes 2013 [Internet]. Seoul: Korean Diabetes Association; 2013 [cited 2015 Jan 22]. Available from: http://www.diabetes.or.kr/pro/ publish/guide_2013.php?mode=list.

14. Jang H, Han JH, Bang JS, Sohn UD. Relationship survey study between diabetic control education and diabetic retinopathy: data from the Korea National Health and Nutrition Examination Survey V. Korean J Clin Pharm 2014;24:33-8.

15. Duncan I, Birkmeyer C, Coughlin S, Li QE, Sherr D, Boren S. Assessing the value of diabetes education. Diabetes Educ 2009;35:752-60.

16. Maine Center for Disease Control and Prevention. Diabetes self-management education barrier study. Augusta: Maine Center for Disease Control and Prevention; 2006.

17. Sim KH, Wang BR, Noh JW, Lee MK, Kwon YD. Diabetes education compliance and knowledge among diabetes patients: analysis of patients who refuse diabetes education at an academic medical center. J Korean Diabetes 2014;15:51-6. 
18. Chasens ER, Enock M, DiNardo M. Reducing a barrier to diabetes education: identifying hearing loss in patients with diabetes. Diabetes Educ 2010;36:956-64.

19. Kim MY, Suh S, Jin SM, Kim SW, Bae JC, Hur KY, et al. Education as prescription for patients with type 2 diabetes mellitus: compliance and efficacy in clinical practice. Diabetes Metab J 2012;36:452-9.

20. Rhee MK, Cook CB, El-Kebbi I, Lyles RH, Dunbar VG, Panayioto RM, et al. Barriers to diabetes education in urban patients: perceptions, patterns, and associated factors. Diabetes Educ 2005;31:410-7.

21. Graziani C, Rosenthal MP, Diamond JJ. Diabetes education program use and patient-perceived barriers to attendance. Fam Med 1999;31: 358-63.

22. Coonrod BA, Betschart J, Harris MI. Frequency and determinants of diabetes patient education among adults in the U.S. population. Diabetes Care 1994;17:852-8.

23. Davis TC, Crouch MA, Wills G, Miller S, Abdehou DM. The gap between patient reading comprehension and the readability of patient education materials. J Fam Pract 1990;31:533-8.

24. Wen LK, Shepherd MD, Parchman ML. Family support, diet, and exer- cise among older Mexican Americans with type 2 diabetes. Diabetes Educ 2004;30:980-93.

25. Sperl-Hillen J, Beaton S, Fernandes O, von Worley A, Vazquez-Benitez G, Parker E, et al. Comparative effectiveness of patient education methods for type 2 diabetes: a randomized controlled trial. Arch Intern Med 2011;171:2001-10.

26. Duke SA, Colagiuri S, Colagiuri R. Individual patient education for people with type 2 diabetes mellitus. Cochrane Database Syst Rev 2009;(1):CD005268.

27. Funnell MM, Brown TL, Childs BP, Haas LB, Hosey GM, Jensen B, et al. National standards for diabetes self-management education. Diabetes Care 2009;32 Suppl 1:S87-94.

28. Lee JJ, Lee HJ, Park EJ. Effect of staged education program for hypertension, diabetes patients in a community (assessment of quality of life using EQ-5D). J Agric Med Community Health 2014;39:37-45.

29. Zanetti ML, Otero LM, Biaggi MV, dos Santos MA, Peres DS, Guimaraes FP. Satisfaction of diabetes patients under follow-up in a diabetes education program. Rev Lat Am Enfermagem 2007;15:583-9. 